\title{
13 \\ VOWEL HARMONY IN WOLOF LOANWORDS
}

Mariame I. Sy

\section{Introduction}

When one language borrows words from another, speakers of the borrowing language typically come upon sounds or sound sequences that are unattested in their native language. These foreign sounds usually undergo a process of adaptation to conform to the phonology of the borrowing language. Such is the case of French words borrowed into Wolof.

Wolof (Niger-Congo) is spoken either as a first or second language by the majority of people in Senegal and Gambia, and also as a minority language in neighboring countries such as Mauritania, Mali, and Guinea. Wolof has been subject to constant and large-scale borrowing of lexical items from French for a great number of years. Over 100 of the 1,500 most frequently used words in modern Wolof are French loans (Dialo 1983: 4-9). In fact, Wolof has borrowed so much from French that younger native speakers in urban areas are unaware of the existence of native words equivalent to the "Wolofized" French terms they use every day. Borrowings have been nativized in spelling, pronunciation, and sometimes meaning. While some older borrowings have been transformed beyond recognition, most remain close enough to the original French words to allow one to observe systematic changes that conform to phonological rules of the borrowing language. These changes involve segmental adaptation as well as syllabic repairs such as cluster resolution by epenthesis. The present paper focuses on how vocalic segments are adapted into the vowel harmony system of the language.

The paper is organized as follows. Section 2 presents an overview of the native harmony system while section 3 discusses loanword harmony patterns that conform to native harmony rules. In section 4 , I consider patterns of systematic 
modification that appear to conflict with what we find in native words. These patterns indicate that there is greater faithfulness to the harmonic feature of long segments, as well as greater markedness for disagreement of mid-vowels. In the analysis presented in section 5, I propose that such patterns arise as a result of interactions between universal faithfulness conditions and the underdetermined nature of specific agreement constraints the hierarchy of which reflects the asymmetry found in the different classes of vowels with regard to their degree of participation in the harmony process.

\section{The Native Harmony System}

Wolof exhibits a pattern of vowel harmony which involves the categorization of all the vowels in the language into two harmonic groups with regard to the feature [ATR] (advanced or retracted tongue root). This feature determines two mutually exclusive sets of vowels.

$$
\begin{aligned}
& \text { +ATR } \\
& i \text { i: } u \text { ur } \\
& \text { e e: } \partial \quad \text { o }
\end{aligned}
$$$$
\varepsilon \quad \varepsilon:
$$$$
\text { -ATR }
$$

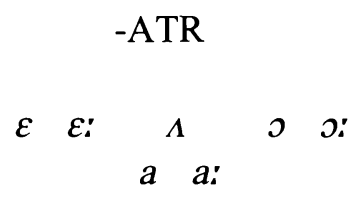

Note that the high vowels have no [-ATR] counterparts and the low vowels no [+ATR] counterparts. This limits the set of alternating vowels to mid vowels.

As described by $\mathrm{Ka}$ (1988) and others, harmony in Wolof is a progressive (left-to-right) process. All vowels trigger harmony in initial position. (By "initial" I mean the first vowel in a word whether preceded by a consonantal onset or not.) The examples below show the vowel of the benefactive suffix $-\Lambda l$ surfacing as [+ATR] when following a [+ATR] root vowel (see 2a), and as [-ATR] after a [-ATR] root vowel (see $2 b)$.

(2)a. [+ATR] Root

li:t-al 'to play the flute for'

tuir-əl 'to spill for'

lett-əl 'to braid for'

batt-al 'to puncture for'

fo:t-əl 'to do laundry for' b. [-ATR] Root

$\begin{array}{ll}\mathrm{ja}^{\mathrm{n}} \mathrm{g}-\Lambda \mathrm{l} & \text { 'to read for' } \\ \mathrm{ja}: \mathrm{y}-\Lambda \mathrm{l} & \text { 'to sell for' } \\ \mathrm{s} \varepsilon: t-\Lambda \mathrm{l} & \text { 'to look for' } \\ \mathrm{f} \Lambda \mathrm{tt}-\Lambda \mathrm{l} & \text { 'to cover a hole for' } \\ \text { bo:t- } \Lambda \mathrm{l} & \text { 'to carry on one's back for' }\end{array}$


Within a fully harmonic tongue root system, one expects to find only vowels that bear the same value for the harmony feature [ATR] to occur within the same domain (or word) as shown in the disyllabic roots in (3). Those are the configurations generally found in Wolof disyllabic roots, sometimes forming minimal or near minimal pairs.

\begin{tabular}{|c|c|c|}
\hline a. [+ATR] Roots & b. $[-\mathrm{AT}$ & R] Roots \\
\hline te:re 'book' & $\operatorname{t\varepsilon r} \varepsilon$ & 'to forbid' \\
\hline 'to wrestle' & $\mathrm{b} \Lambda \mathrm{r} \varepsilon$ & 'to be a lot' \\
\hline ‘vapor' & co:nว & 'tiredness' \\
\hline 'hyena' & bakka:r & 'sin' \\
\hline
\end{tabular}

While words containing exclusively mid vowels (e, $\varepsilon, \partial, \Lambda, o, 0)$ always surface as fully harmonic forms, those containing high vowels $/ \mathrm{i} /$ and $/ \mathrm{u} /$ or the low vowel /a/ in medial position may surface as disharmonic forms. This state of affairs stems from the asymmetry in the system, namely the fact that high vowels and low vowels have no counterparts with the opposite tongue root value, and therefore remain advanced or retracted respectively. Although high and low vowels both contribute to producing disharmonic forms, they do so in quite different ways.

\subsection{High Vowels: Transparency}

Initial high vowels $/ \mathrm{i}$ and $/ \mathrm{u} /$ trigger harmony on the vowels to their right. When occurring in medial position, however, these high vowels are transparent to harmony: they neither trigger nor block the process.

\begin{tabular}{|c|c|c|c|c|}
\hline \multicolumn{5}{|c|}{ damina- $\Lambda$ l } \\
\hline & ta:xuran- $\Lambda$ l & $\rightarrow$ & ta:xuranıl & 'to sing for' \\
\hline & $\Lambda$ si:re- $\Lambda \mathrm{l}$ & $\rightarrow$ & $\Lambda$ si:re:l & 'to insure for' \\
\hline & $\Lambda \mathrm{ni}: \mathrm{n}-\Lambda \mathrm{l}$ & $\rightarrow$ & $\Lambda$ ni:n $\Lambda 1$ & 'to put make up for' \\
\hline b. & sopp-i-ə:n & $\rightarrow$ & soppiwว:n & 'changed' \\
\hline & sepp-i-ə:n & $\rightarrow$ & seppiwっ:n & 'took out of a liquid \\
\hline & te:r-u-o:n & $\rightarrow$ & te:ruwo:n & 'welcomed' \\
\hline & da:n-u-o:n & $\rightarrow$ & da:nuwo:n & 'fell' \\
\hline & f $\Lambda 1-u-\jmath: n$ & $\rightarrow$ & fsluwo:n & 'came to power' \\
\hline
\end{tabular}


Such behavior is apparent both root-internally and across morphemes. The examples in (4a) show that the medial high vowels inside the root forms neither incur harmony effects from the initial [-ATR] vowel, nor do they trigger harmony on either the final vowel of the root or the vowel of the benefactive affix. Similarly, in the derived forms in (4b) the affixes $-i$ (reversive) and $-u$ (transitivizer) fail to trigger harmony on the following past tense suffix $-(w)$ o:n which surfaces with the same [-ATR] value as the initial vowel of the root.

\subsection{Low vowels: Opacity}

All vowels in root-initial position trigger harmony to their right, and low vowels are no exception. In medial position, on the other hand, they do not harmonize with a preceding vowel and, unlike the high vowels, they block the spread of the ATR feature through them to the vowels immediately to their right.

(5) Root + 'iterative'-a:t + 'benefactive'
a. bind-a:t- $\Lambda$ l
'write again for'
do:r-a:t- $\Lambda$ l
'hit again for'
je:m-a:t- $\Lambda$ l
'try again for'
mu:r-a:t-ıl
'cover again for'

Root + 'iterative'-a:t + 'past tense'
b. bind-a:t-o:n
'wrote again'
do:r-a:t-o:n
'hit again'
je:m-a:t-o:n
'tried again'
mu:r-a:t-o:n
'covered again'

The examples in (5a) show the low vowel /a/ following initial [+ATR] vowels without incurring any harmony effects from the latter. Furthermore, although the vowel of the benefactive suffix surfaces as [+ATR] when it directly attaches to [+ATR] roots, as in (2a), it fails to harmonize in (5a), in which it is separated from the same root forms by the affix containing the low vowel. The same pattern can be observed with the past tense suffix in (5b).

\subsection{Basic Assumptions about the Wolof System}

A number of proposals have been made within Optimality Theory to account for patterns of progressive harmony such as the one displayed in the Wolof system. Earlier OT accounts of Niger-Congo languages (Archangeli \& Pulleyblank 1994, Pulleyblank 1994, Akinlabi 1997) are based on the premise that harmony is a result of feature alignment. Later proposals, however, argue that vowel harmony and other types of assimilation are driven by the markedness constraint AGREE $\mathrm{F}$ which requires two articulatorily adjacent segments to have the same specification for a given feature (Bakovic 2000).

Following this proposal, we assume that Wolof harmony is driven by AGREE (ATR), one of the various AGREE (F) constraints which refer to segmental features, 
see (6). Since the initial vowel of root forms generally determine the harmonic feature of a word, we also assume that there is a positional faithfulness constraint to the harmonic feature of word-initial vowels, see (7).

(6) AGREE (ATR): All vowels in a given word must bear the same [ATR] specification.

(7) IDENT (ATR Ol): The [ATR] specification of the initial vowel of a word is preserved in the output.

Second, we consider the behavior of high and low vowels within the harmony process in Wolof to be related to universal acoustic and articulatory enhancement relations between lowness and retraction of the tongue root, and, conversely, highness and advancement of the tongue root (Ladefoged 1972, Archangeli \& Pulleyblank 1994). Such behavior is, in fact, not uncommon in tongue root harmony languages. Yoruba (Niger Congo, Pulleyblank 1996), for example, lacks both low [+ATR] and high [-ATR] vowels; Diola Fogny (Niger Congo, Bakovic 2000) and Maasai and Turkana (Nilotic, Bakovic 2000) all lack low [+ATR] vowels. These conditions have been translated in Optimality Theory terms as multiple-feature markedness constraints against segments with the opposite harmonic feature. In the case of Wolof, such constraints may be stated as follows.

(8) * [HI, -ATR]: A high vowel may not bear the feature [-ATR]

(9) * [LO, +ATR]: A low vowel may not bear the feature [+ATR]

\section{Loanword Harmony}

Traditionally, the main concerns of loanword phonology research have been whether the adaptation process is governed by generative rules or constraints, and whether or not these constraints are universal (Paradis \& Lacharité 1997). More recently, proposals have been made within OT claiming that loanwords are subject to the same hierarchy of constraints as native words, with a possible promotion of faithfulness in the foreign-word hierarchy (Ito \& Mester 1998). One implication of such an approach is that in adapting these foreign words, speakers apply their implicit phonological knowledge so that the adaptation process conforms to the native phonological system. However, in case it doesn't and we find patterns that appear to contradict the native system, we expect such emergent 
patterns to reveal aspects of the grammar that are not evident from looking at the native phonology alone. Patterns of this kind are likely to arise when the languages involved have substantially different phonologies.

If we consider loanword adaptation processes to follow from well-formedness constraints on output forms, then we might consider OT (McCarthy \& Prince 1993, Prince \& Smolensky 2004) an adequate tool for describing such processes, given its output-oriented character. In what follows, we argue that vowel adaptation in Wolof loanwords from French result from such well-formedness constraints, namely those constraints that militate against disagreement of any vowels within the same word with regard to the feature [ATR]. Moreover, it is argued that this adaptation process is subject to faithfulness constraints that arise due to a direct correlation between tense/lax values in the source language and tongue root advancement/retraction values in the borrowing language.

\subsection{Vowel Correspondences}

Consider the following data.

\begin{tabular}{|c|c|c|c|c|c|}
\hline $\begin{array}{c}\text { (10) a. French } \\
/ \text { pnø/ }\end{array}$ & $\begin{array}{l}\text { Wolof } \\
\text { [pənə] }\end{array}$ & 'tire' & $\begin{array}{l}\text { French } \\
\text { /afer/ }\end{array}$ & $\begin{array}{l}\text { Wolof } \\
{[\Lambda f \varepsilon: r]}\end{array}$ & 'business' \\
\hline /fœetr/ & [fə:tər] & 'felt' & $/ \mathrm{metr} /$ & [me:t $\Lambda \mathrm{r}]$ & 'meter' \\
\hline /bœr/ & [bə:r] & 'butter' & /Elev/ & [Ele:w] & 'pupil' \\
\hline /pyr/ & [pi:r] & 'pure' & $/ \mathrm{p} \varepsilon \mathrm{r} /$ & [pe:r] & 'pair' \\
\hline /pir/ & [pi:r] & 'worst' & /por/ & [po:r] & 'harbor' \\
\hline to/ & [moto] & 'motorbike' & /bor/ & [bo:r] & 'edge/side' \\
\hline & [de:] & 'thimble' & $/ \operatorname{tr} \varepsilon /$ & [tere] & 'line' \\
\hline /pəti/ & [pəti] & 'small' & /pomdəter/ & [pombite:r] & 'potatoes' \\
\hline
\end{tabular}

Comparing the French forms to their Wolof counterparts we find systematic vowel correspondences that reflect the types of changes that French vowels undergo to conform to Wolof phonology. First, certain contrasts in French are neutralized in Wolof. The French front high rounded vowel $/ \mathrm{Y} /(=\ddot{\mathrm{u}})$ (which Wolof does not have) and its unrounded counterpart /i/ are both realized in Wolof as front high unrounded /i/. Wolof also lacks mid front rounded vowels, so the distinction between the French mid front rounded vowels $/ \varnothing /$ and /œ/ and the mid central vowel $/ \partial /$ is neutralized: all three vowels surface in Wolof as /ə/, e.g., [bə:r] 'butter'.

Second, although length is not contrastive in French, some contextual lengthening occurs in stressed vowels in word final position and in closed 
syllables. Lengthened vowels of these types are always realized long in Wolof, even when the resulting segment is not attested in the native phonology as in the case of $/ 2: /$.

The third important fact to be noted from (10) is the mapping of French tense and lax vowels to [+ATR] and [-ATR] vowels in Wolof respectively. ${ }^{1}$

In light of these facts, one might be drawn to the conclusion that an account of harmony in Wolof loanwords must necessarily include input to output correspondence constraints relating tenseness and laxness in French input vowels to [ATR] values in Wolof output vowels. ${ }^{2}$ However, assuming that foreign sounds are perceived as underlying forms (Hyman 1970), one might rather claim that the borrowed forms that constitute the input to the speaker's grammar have already been mapped to Wolof vowels, that is, the input tense vowels are heard as [+ATR] vowels and lax ones as [-ATR]. Such an approach adequately eliminates the complexity that mapping constraints would bring to the grammar while allowing a single ranked hierarchy of constraints. The following section motivates this approach.

\subsection{Native-like Patterns}

Certain loanwords display exactly the same patterns of harmony found in native words. For example, disyllabic French words which contain mid vowels contrasting with respect to tenseness are adapted into Wolof as perfectly harmonic roots the [ATR] feature of which is determined by the initial vowel of the word. But before we consider these forms let's first examine monosyllabic French forms which are adapted as disyllabic roots by vowel epenthesis.

3.2.1. Epenthetic vowels. Wolof does not allow consonant clusters in syllableinitial position, and very few clusters are tolerated in coda position. French loanwords containing clusters are therefore repaired via epenthesis, either by prothesis where there is an $\mathrm{sC}$ cluster (see 11b) or else by insertion (see 11a).

1 The question was brought to my attention whether the Wolof distinction is not simply tense/lax. Experimental data (Sy n.d.) show that the acoustic properties of Wolof vowels closely parallel those of Akan vowels (Lindau 1975, 1979) with the distinction between the two sets of vowels mainly reflected in their first formant values while second formant values show no significant difference. Acoustic studies of tense/lax opposition in English, for example (Halle \& Stevens 1969, Ladefoged et al. 1972), have found greater differences in tongue dorsum height (and hence second formant values).

${ }^{2}$ This approach was taken in an earlier version of this research presented at SWOT 8 (Southwest Workshop on Optimality Theory) 2003, University of Arizona. 
(11) French

$\begin{array}{ll}\text { a. } / \text { tre/ } & \text { 'line' } \\ \text { /pli/ } & \text { 'fold' } \\ \text { /brəve/ 'HS diploma' } & \text { 'bluz/ 'smock' } \\ \text { /drog/ } & \text { 'drugs' }\end{array}$

Wolof

[tere]

[pili]

[bərəwe]

[bulu:s]

[dorog]
French

b. /spor/ 'sports'

/staty/ 'statue'

/staz/ 'internship'

/steno/ 'stenographer'

/stilo/ 'pen'
Wolof

[Espo:r]

[Est $\Lambda t i]$

[Esta:s]

[esteno:]

[estilo:]

The epenthetic vowel inserted in initial clusters is identical to the following vowel (except that $/ \Lambda$ normally appears instead of $/ a /$ ). By contrast, the prothetic segments are all mid front vowels conditioned by harmony. The tongue root value of the prothetic vowel is determined by that of the initial vowel of the input form. Thus, the vowels $/ \varepsilon /$ and /e/ in [espo:r] and [estilo:] contrast with respect to [ATR] value because the initial vowels $/ \mathfrak{o} /$ and $/ \mathbf{i} /$ in the corresponding input forms contrast with respect to tenseness value.

The working of harmony in epenthetic segments can also be seen in the treatment of final clusters. In such forms, mid central vowels are inserted. These alternate to harmonize with the vowel of the root. The epenthetic mid central vowels in (12) display the same pattern as the prothetic mid front vowels in (11), i.e., they surface as [-ATR] $/ \Lambda /$ in forms with lax input vowels, but $[+$ ATR] $/ 2 /$ in those with tense input vowels.

\begin{tabular}{|c|c|c|c|c|c|c|}
\hline (12) & $\begin{array}{l}\text { French } \\
\text { /letr/ }\end{array}$ & 'letter' & $\begin{array}{l}\text { Wolof } \\
\text { [le:t } \Lambda \mathrm{r}]\end{array}$ & $\begin{array}{l}\text { French } \\
\text { /litr/ }\end{array}$ & 'liter' & $\begin{array}{l}\text { Wolof } \\
\text { [li:tər]] }\end{array}$ \\
\hline & $/ \operatorname{tabl} /$ & 'table' & {$[\mathrm{ta}: \mathrm{b} \wedge \mathrm{l}]$} & /fœetr/ & 'felt' & [fə:tər] \\
\hline & /mכ̃tr/ & 'watch' & {$[\mathrm{mont} \Lambda \mathrm{r}]$} & /livr/ & 'pound' & [li:bər]] \\
\hline & /tabl/ & 'table' & [ta:bsl] & /pudr/ & 'powder' & [pu:dər] \\
\hline
\end{tabular}

\subsubsection{Non-epenthetic vowels}

3.2.2.1. Mid vowels: full participation. Loanwords containing only midvowels display perfect harmony, regardless of the fact that they may contain vowels with opposite tenseness values in French. This behavior parallels that of native forms of the same type. As can be noted from the data in (13), all these disyllabic roots contain a tense and a lax vowel in the source language. Nonetheless, every one of these forms surfaces in Wolof as a perfectly harmonic root with all vowels bearing the same [ATR] value as the initial vowel of the word. This is in accordance with the left-to-right spreading observed throughout in the system. 


\begin{tabular}{|c|c|c|c|}
\hline (13) & $\begin{array}{l}\text { French } \\
\text { /bato/ }\end{array}$ & 'boat' & $\begin{array}{l}\text { Wolof } \\
\text { [b } \Lambda \text { to }]\end{array}$ \\
\hline & /kado/ & 'gift' & [kıdo] \\
\hline & /г̃po/ & 'tax' & [lempo] \\
\hline & /dele/ & 'deadline' & [dele] \\
\hline & /sere/ & 'to tighten' & [sE:rE] \\
\hline
\end{tabular}

Similarly, derived forms from this type of borrowed root remain harmonic showing spreading of the harmonic feature of the initial vowel onto the vowel of the suffix. The data in (14) illustrate such cases with the benefactive suffix.

(14) French

/aroze/ 'to water'

/sere/ 'to tighten'

/bœr / 'butter'

/dore/ 'golden'

/pudr/ 'powder'

/mœbl/ 'furniture'
Wolof + 'benefactive' $-\Lambda \mathrm{l} \sim-$-əl

\begin{tabular}{|c|c|c|}
\hline $\operatorname{ar\jmath :S\varepsilon -\Lambda l~} \rightarrow$ & [aro:se:l] & 'to water for' \\
\hline 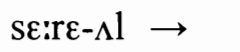 & [se:re:l] & 'to tighten for' \\
\hline bə:re-əl $\rightarrow$ & [bə:re:1] & 'to butter for' \\
\hline 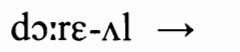 & [do:re:l] & 'to golden for' \\
\hline u:dər-əl & [pu:dərəl] & 'to powder for' \\
\hline mə:bəle-əl $\rightarrow$ & [mə:bəle:l] & 'to furnish for' \\
\hline
\end{tabular}

3.2.2.2. High vowels: transparency. In some loanwords, high vowels display the same behavior as in native words, i.e., they induce harmony in root initial position, and are transparent in non-initial position.

(15) French

a. /sire/

/uvertyr/

/biye/

/pike/

/brike/

/priyorite/
Wolof

'to polish' [si:re]

'opening'

'ticket'

'peg'

'lighter' [uweti:r]

[biye]

[pikket]

[birike]
French

b. /opital/

/serpiyer/ /pomdəter/

/kalite/

/kraJwar/

/ardwaz/
Wolof

'hospital' [opita:l]

'floorcloth' [serpiye:r]

'potatoes' [pombite:r]

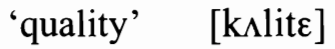

'spittoon' [kıra:suwa:r] 'slate'

[Arduwa:s]

Initial high vowel French forms are adapted in Wolof as harmonic [+ATR] roots, regardless of the tense value of the source non-initial vowels. Forms such as /biys/ and /pike/, which contain a tense initial high vowel and a lax final vowel (which should be adopted as [-ATR]), surface in Wolof as perfectly harmonic [biye] and [pikket]. In (15b) medial high vowels remain advanced while the vowels on each side of them are retracted, thus displaying the typical transparent behavior found in the native harmony system. 
3.2.2.3. Low vowels: opacity. In a number of loanwords low vowels conform to the native harmony pattern as well; they remain systematically retracted, and induce harmony to their right.
(16) French
Wolof
French
Wolof
a. /siraz/ 'shoe polish'
[si:ra:s]
b. /bulãze/ 'baker'
[mbula:jns
/limonad/ 'soda'
[limona:t]
/bwat/ 'box'
[buwa:t]
/depãse/ 'to spend'
[deppa:nse]
/teyatr/ 'theater'
[tiya:t $\Lambda$ ] /portmãto/ 'coat rack'
[port $\Lambda$ ma:nto]
/istwar/ 'story'
[istuwa:r]
/viraz/ 'turn'
[wi:ra:s]
/derãze/ 'to bother'
[dera:nse]
/kõdane/ 'to board up'
[kon da:ne]
/pulaye/ 'chicken coop' [pula:ye]

In the above data, forms such as [bulãze] in which the final vowel is a tense mid vowel and therefore should be adapted as [+ATR], surface with this vowel carrying the [-ATR] feature of the preceding low vowel /a/, not that of the rootinitial [+ATR] vowel.

Summarizing so far, we have shown that loanwords display native-like harmony patterns, showing left to right spreading of the harmony feature of wordinitial vowels, as well as the particular characteristics of high and low vowels in medial position, i.e., transparency vs. opacity. In loanwords containing epenthetic vowels that are not exact copies of the root vowel, the harmonic feature of the epenthetic vowel is determined by that of the root vowel. Furthermore, when a particular input form contains a disharmonic mid-vowel (that is when its first vowel has a tongue root value opposite to that of a following mid vowel) the noninitial mid vowel is further repaired to conform to the fully harmonic behavior of its class in the native system. However one unexpectedly finds borrowings in which the same class of vowels appear to be in violation of harmony constraints, words with mid vowels that do not undergo repair to agree with a preceding vowel, but rather remain faithful to their input feature value. We turn to those patterns now.

\section{Non-Native-like Patterns}

\subsection{High Vowels: Lack of Transparency and "Triggerancy"}

In some loanwords high vowels behave most unexpectedly: they neither trigger harmony when occurring in the initial syllable, nor do they allow the opposite tongue root feature to spread through them when they appear in wordmedial position. 


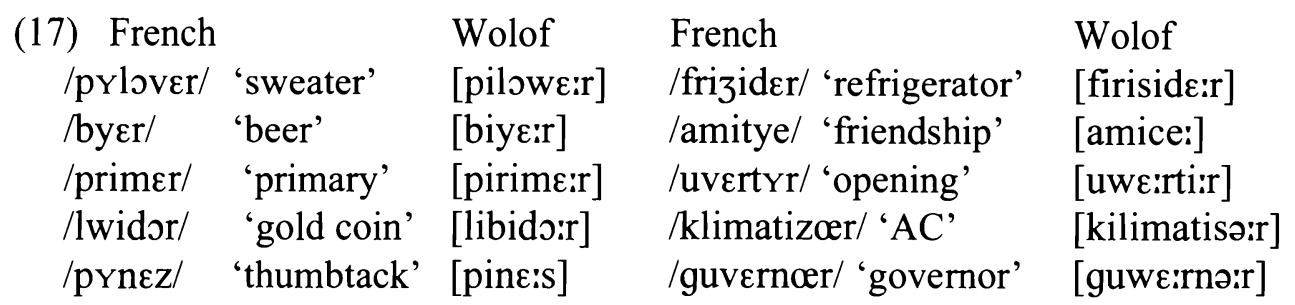

The Wolof forms in (17) are disharmonic because the high vowels fail to induce harmony on one of the following mid vowels. Native forms of this shape are not attested. Moreover, as previously discussed, mid vowels in non-initial position normally do undergo repair to harmonize with the vowel that precedes them (e.g., $/$ pike/ $\rightarrow$ [pikket] vs. /primer/ $\rightarrow$ [pirime:r]). While the reason for such behavior may not be immediately apparent, a comparison of the data set in (17) to one seen in (18) reveals a pattern which indicates that the difference between the two types of vowels involved in these structures may be of consequence.
(18)

\begin{tabular}{|c|c|c|c|c|}
\hline $\begin{array}{l}\text { French } \\
\text { kalite/ } \\
\text { biye/ }\end{array}$ & $\begin{array}{l}\text { 'quality' } \\
\text { 'ticket' }\end{array}$ & $\begin{array}{l}\text { Wolof } \\
\text { [kAlite] } \\
\text { [biye] }\end{array}$ & 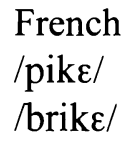 & $\begin{array}{l}\text { 'peg' } \\
\text { 'lighter' }\end{array}$ \\
\hline
\end{tabular}

The forms in (18) are those in which, by virtue of harmonizing with a preceding vowel, an input French mid vowel ends up surfacing in Wolof with the opposite tongue root feature from that expected given the tenseness of its source. In other words, these mid vowels, all of which are short, violate faithfulness to satisfy harmony markedness requirements. By contrast, the vowels in (17), which satisfy faithfulness to their input value but violate harmony constraints, are all long. This suggests that there is a condition requiring faithfulness to the tongue root specification of long vowels which outranks the basic harmonic markedness constraints. Although such condition is not apparent in native words, it is very much alive in loanwords, forcing non-native-like behavior both in mid and in low vowel forms.

\subsection{Low Vowels: Lack of Opacity}

The loanwords in (19) display a pattern similar to that of the high vowel forms discussed above in that their low vowels fail to trigger harmony in the vowels located to their right as would be expected given the usual behavior of this class of vowels in native forms. 


$\begin{array}{lll}\text { (19). French } & & \text { Wolof } \\ \text { /ordinatcr/ 'computer' } & \text { [ordina:tə:r] } \\ \text { /vãtilatcer/ } & \text { 'fan' } & \text { [wantila:tə:r] } \\ \text { /senatcr/ } & \text { 'senator' } & \text { [sena:tə:r] } \\ \text { /drapo/ } & \text { 'flag' } & \text { [d } \Lambda \text { ra:po:] } \\ \text { /flãbo/ } & \text { 'torch' } & \text { [f } \Lambda \text { lambo:] } \\ \text { /plato/ } & \text { 'tray' } & \text { [p } \Lambda \text { la:to:] } \\ \text { /klimatizcer/'air conditioner' } & \text { [kilimatisə:r] }\end{array}$

As in the disharmonic cases described in (17), the disagreeing vowel to the right in the forms in (19) is a long vowel. The harmonic vowels in the same position in (16) are all short mid vowels. These facts further support the claim that there is a constraint that militates against altering the [ATR] specification of long vowels.

\subsection{Mid Vowels: Regressive Harmony}

Among loanwords that do not conform to the native harmony pattern, those containing exclusively mid vowels display the most non-native-like behavior considering that they seem to have created regressive harmony of their own. The forms in (20a) show that non-final mid-vowels that are tense in French and therefore should be adapted as [+ATR] in Wolof harmonize with the [-ATR] vowel in word final position by means of right-to-left spreading, a pattern that is not attested in native words, nor any other type of borrowed words.

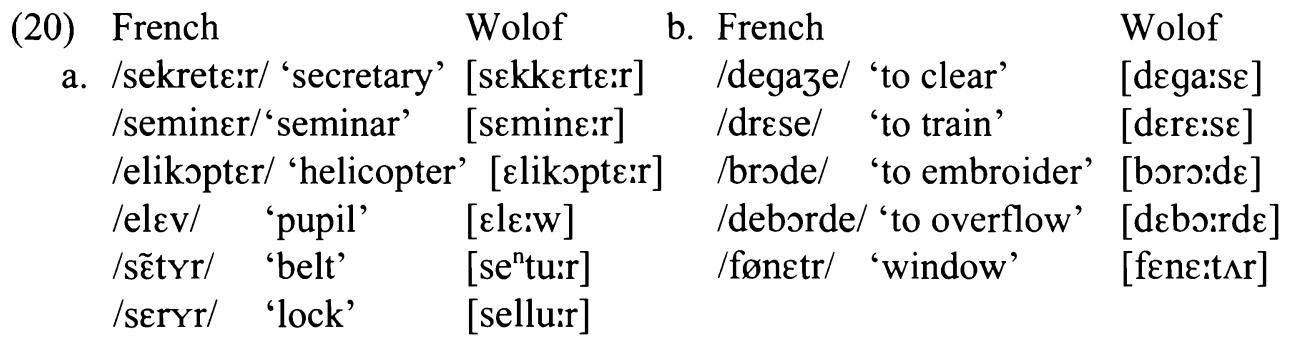

c. French /vinegr/ /trene/ /maternite/
Wolof

[bine:g $\Lambda$ ]

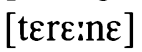

[mate:rnite]

Considering the above more carefully, we find that whether we get progressive, regressive, or bidirectional harmony depends on the position of the long vowel 
vis-à-vis the would-be-disharmonic vowels. Thus, in cases such as (20a) in which the long vowel is the rightmost vowel and all disharmonic input vowels precede it, right-to-left spreading obtains. Conversely, if the long vowel is to the left of the target disharmonic input vowel as in (20c), harmony proceeds in the reverse direction. By the same logic, we get harmony in both directions, i.e., left-to-right and right-to-left spreading, if the long vowel is medial and is flanked by disharmonic vowels on each side as in (20b). The choice of which vowels get altered is conditioned by the faithfulness constraint to the [ATR] feature of long vowels. This condition, formalized in (21) ensures that the long vowel becomes the harmony trigger regardless of its position within the word.

(21) IDENT [ATR]LG: The [ATR] specification of a long vowel must be preserved in the output.

The crucial point is that all observed non-native-like patterns result from greater faithfulness to the tongue root feature of long vowels.

One interesting fact that should be noted is that the vowels that are adapted as long segments in Wolof correspond in the French word to either lengthened vowels in closed syllables or final stressed vowels. This suggests that the failure of long vowels to harmonize is due to universal conditions of inalterability of salient segments. The effects of such conditions in Wolof loanwords are similar to what is found in Tigre (Steriade 1987), where rounding harmony fails to apply to long vowels. Such resistance to harmony has been analyzed in terms of interactions between a positional faithfulness and a constraint that induces rightward harmony (McCarthy \& Prince 1993). This positional faithfulness presumably reflects the greater perceptibility of vowel quality distinctions in long vowels (Kaun 1994). Beckman (1999) points to asymmetries in phonological systems which can be related to positions in structure, suggesting that some positions are privileged, others non-privileged. In privileged positions contrasts are maintained and segments resist modification and act as triggers; in nonprivileged positions contrasts are neutralized and segments are vulnerable and become targets. Examples of privileged position reflecting such characteristics are root vs. affix, onset vs. coda, and stressed versus unstressed syllable. Beckman argues that these positional differences are the effects of salience (psycholinguistic or perceptual). These conditions can be implemented in Wolof by separating out from the general IDENT (F)-SALIENT, a positionally-specified sub-case IDENT (ATR)-LG. 
The question now arises as to why this condition forces bidirectional harmony only in one class of vowel, namely mid-vowels. I suggest that these facts follow from the underdetermined nature of harmony constraints in Wolof as a consequence of the asymmetry in the system.

\section{Analysis}

\subsection{Emergence of Underdetermined Harmony Constraints}

The faithfulness requirement to the tongue root feature of long vowels seems to force different patterns of harmony depending on the type of vowels involved in the structure. While in words containing vowels of different height the occurrence of a long vowel may result in a disharmonic form, in words containing strictly mid-vowels disharmony never results; instead such words surface as fully harmonic forms bearing the [ATR] specification of the long vowel, regardless of the fact that the short vowels involved may have been of opposite tenseness values than the long vowel.

If the constraint in (21) were the only condition to be satisfied, nothing would prevent a form such as French [sekrete:r] to surface as Wolof suboptimal * [sekrete:r] which in terms of faithfulness to the input incurs less violations than optimal [sekkerte:r]. In fact the optimal form [d $\Lambda$ ra:po:] in (19) is exactly like *[sekrete:r]: its final long vowel simply remains faithful to the input harmonic feature without causing the initial mid vowel to harmonize with this feature. The only difference between these two forms is that the former contains only mid vowels while the latter contains a low vowel. These facts suggest that there must be some other condition requiring mid-vowel forms to be fully harmonic. Such condition is not evident in the native phonology because mid-vowels are the only class of vowels that fully comply with harmony requirements in the Wolof system. Roots, as well as derived forms that contain only mid vowels always surface as fully harmonic forms; and all disharmonic forms in Wolof either contain a high transparent vowel or a low opaque vowel. Consequently, it is never the case that Wolof speakers are faced with either a disharmonic mid-vowel root or a disharmonic input containing exclusively mid-vowels in the native lexicon. Hence, there is no evidence of such constraint in action.

However, given the fact that some French input forms contain contrasting vowels with regard to tenseness which are mapped to contrasting [ATR] values in Wolof, disharmonic mid-vowel forms occur in loans. Such forms have to be repaired to conform to the harmony system. In this repair process, universal conditions as well as underdetermined grounding conditions emerge to resolve 
conflicts in input structures from loans that are unattested in the native phonology.

Considering the make-up of the Wolof system, it is reasonable to assume that there is a family of agreement constraints which refer to vowel height, the ranking of which reflects the asymmetry found in the harmony system regarding the participation of each set of vowels. Among these constraints, the highest ranked is the one referring to mid vowels, AGREE (MID,ATR). Mid vowels being the only vowels which fully participate in the harmony system, a disharmonic string containing such vowels exclusively is more marked than disharmonic strings containing either high or low vowels. Thus mid vowels are subject to greater markedness conditions with respect to disagreement than high and low vowels. For the purpose of this paper, however, we will not be concerned with the irrelevant non-emergent AGREE (HIGH, ATR) and AGREE (LOW, ATR). (MID, ATR) requires that a harmony domain containing mid vowels be fully harmonic with respect to the feature [ATR].

(22) AGREE (MID, ATR): Mid vowels within the same domain must be fully harmonic.

With these assumptions at hand we can now proceed to demonstrate the interaction of this harmony constraint with the universal faithfulness condition in (21) and the more general conditions of Wolof vowel harmony.

\subsection{Constraints Interaction}

The two types of constraints that have emerged from the Wolof loanword data fall into the two broad categories of universal constraints as defined in Optimality Theory: Markedness and Faithfulness. Crucially, while in native words universal markedness conditions such as * $[H I,-A T R]$ and * [LO, +ATR] dominate both the faithfulness constraint which requires preservation of the tongue root value of initial vowels (IDENT [ATR $\sigma 1]$ ) and the general feature agreement constraint (AGREE [ATR]), the loanword adaptation process requires both universal faithfulness (IDENT [ATR] $L G$ ) and the vowel-specific markedness condition on feature agreement (AGREE (MID)) to dominate the more general makedness and faithfulness conditions.

(23) IDENT [ATR,LG], AGREE (MID) >> IDENT [ATR OI], AGREE [ATR] 
Ranking the more general harmony constraints IDENT [ATR Ol] and AGREE [ATR] over the more specific $A G R E E$ (MID) and IDENT [ATR, LG] results in deriving fully harmonic, but sub-optimal candidate [sekkerte:r] as the winner while the optimal candidate [sekkerte:r] loses by virtue of not preserving the [ATR] feature of the initial input vowel. The reverse ranking, on the other hand derives the correct output form because it allows harmony to be determined by the long segment. Other possible disharmonic candidates, even if they faithfully preserve the harmonic feature of the long segment would be ruled out by the markedness constraints requiring harmony.

Furthermore, within the specific constraints, faithfulness must dominate markedness (IDENT [ATR,LG] >> AGREE (MID,ATR)), otherwise optimal candidates such as [guve:rnə:r] would lose to sub-optimal but fully harmonic [guvə:rnərr] which fares worst only because it fails to preserve the harmonic feature of one of its long segments. In addition, this ranking also allows cases such as [d $\Lambda$ ra:po:] in which a short mid vowel and a long mid vowel disagree to emerge as optimal.

(24) IDENT [ATR ,LG] >> AGREE (MID,ATR) > IDENT [ATR Ol], AGREE [ATR]

Finally, the universal markedness constraints * $[H I,-A T R]$ and * [LOW, $+A T R]$ must necessarily rank above all constraints since they are never violated in Wolof, and thus remain undominated. These rankings give us the complete hierarchy in (25) below.

$(25){ }^{*} H I[-A T R],{ }^{*} L O W[+A T R]>>I D E N T[A T R, L G]>>$ AGREE $(M I D, A T R)>>I D E N T$ [ATR $\sigma l>>$ AGREE [ATR]

\section{Conclusion}

This paper has provided evidence in support of the claim that loanword adaptation is subject to the same hierarchy of constraints available in the native phonology. The Wolof data indicate that emergent patterns that appear to contradict the native system arise as a result of interactions between universal conditions and facets of Wolof harmony grammar that are underdetermined by the native-language learning data. These emergent patterns have unveiled some important facts about the make-up of the vowel harmony system of Wolof. The first is that there is greater faithfulness to long segments, a condition that is not evident from looking at native words alone. We have argued this condition to arise as a result of universal constraints on inalterability of salient segments. The 
second fact is that the harmony system imposes greater disharmony markedness in mid vowels, a condition that is a consequence of the asymmetry in the system. Because mid vowels are always fully harmonic, and high and low vowels never alternate, there is no evidence of the effects of such constraint in the native language data. However, the introduction of disharmonic inputs that would otherwise never arise in the native phonology has triggered the emergence of these constraints, and thus provided important insights into the finer structure of the Wolof harmony system, i.e., one in which both markedness and faithfulness dominate the basic harmony conditions.

\section{REFERENCES}

Akinlabi, Akinbiyi. 1997. "Kalabari vowel harmony." The Linguistic Review 14: 97-138.

Archangeli, Diana, and Douglas Pulleyblank 1994. Grounded Phonology. Cambridge, MA: MIT Press.

Bakovic, Eric. 2000. Harmony, Dominance and Control. Ph.D. dissertation, Rutgers University.

Dialo, Amadou. 1983. Éléments systematiques du wolof contemporain. Dakar: Centre de Linguistique Appliquée de Dakar W 24.

Fall, Arame, R. Santos, and J. Doneux. 1990. Dictionnaire wolof-français. Paris: Karthala.

Halle, Morris, and K. Stevens 1969. "On the feature advanced tongue root." In Morris Halle, From Memory to Speech and Back: Papers on Phonetics and Phonology, 1954-2002. Berlin. Mouton de Gruyter (2002).

Hyman, Larry. 1970. "The role of borrowings in the justification of phonological grammars." Studies in African Linguistics 1: 1-48.

Ka, Omar. 1988. Wolof Phonology and Morphology: A Non-linear Approach. Ph.D. dissertation, University of Illinois.

Kaun, Abigail. 1994. "An Optimality Theoretical account of rounding harmony typology." In Proceedings of the Thirteenth West Coast Conference on Formal Linguistics (WCCFL 13), pp. 78-92.

. 1995. "Auditory and articulatory constraint interaction in harmony." Unpublished colloquium delivered at Yale University Dept. of Linguistics.

Ladefoged, Peter, Joseph DeClerk, Mona Lindau, and George Papçun. 1972. "An auditory-motor theory of speech production." UCLA Working Papers in Phonetics 22: 48-75. 
Lindau, Mona 1975. "Features for Vowels." UCLA Working Papers in Phonetics 30.

. 1979. "The feature expanded." Journal of Phonetics 7(2): 163-76.

McCarthy, John, and Alan Prince. 1993. "Generalized alignment." Yearbook of Morphology, pp. 79-153.

Monro, Pamela, and Dieynaba Gaye, 1997. Ay Baati Wolof: A Wolof Dictionary. UCLA Occasional Working Papers in Linguistics 1.

Paradis, Carole, and Darlene Lacharité. 1997. "Preservation and minimality in loanword adaptation." Linguistics 33: 379-430.

Prince, Alan, and Paul Smolensky. 2004. Optimality Theory: Constraint Interaction in Generative Grammar. Malden, MA: Blackwell.

Pulleyblank, Douglas. 1994: "Neutral vowels in Optimality Theory: A comparison of Yoruba and Wolof." Canadian Journal of Linguistics 41: 295347.

Steriade, Donca. 1987. "Locality conditions and feature geometry." In Proceedings of NELS 17, ed. by, Joyce McDonough and Bernadette Plunkett, pp. 595-618. Graduate Linguistics Student Association, University of Massachusetts, Amherst.

Sy Mariame I. n.d. "Is there long distance harmony in Wolof?" Unpublished ms., UCLA.

Mariame I. Sy

UCLA

email: misy@humnet.ucla.edu 